\title{
Physical Properties of Screen-Printed Polycrystalline Cadmium Sulphide Films for Solar Cells
}

\author{
Bhatu Yashwant Bagul ${ }^{*}$ \\ ${ }^{1}$ Vasantrao Naik Arts, Commerce and Science College Shahada, 425409, M.S., India \\ *Corresponding author Email: bybagul@gmail.com
}

Received: 2.8.2021; Revised: 16.10.2021; Accepted: 5.11.2021

CSociety for Himalayan Action Research and Development

\begin{abstract}
In the present work Cadmium sulphide (CdS) nanopowder was synthesized by chemical coprecipitation route and films were synthesized by non-vacuum based and cost feasible screen-coating route. Most favorable conditions for synthesis of good quality screen-coating films were obtained. Deposited CdS films were investigated by XRD, FESEM, EDAX, UV-vis and two probes methods for microstructural, morphological, elemental, optical and electrical properties. The XRD studies reveals that the films have polycrystalline nature showing hexagonal structure with preferred orientation of grains along (002) plane for powder \& (101) plane for CdS film. The morphological analysis showed the films are homogeneous with nearly spherical clusters. Elemental analysis confirmed the existence of $\mathrm{Cd}$ and $\mathrm{S}$ elements in the films with $\mathrm{Cd} / \mathrm{S}$ ratio is 0.74 . The optical properties of the films were investigated through absorbance \& transmittance measurement. The optical direct band gap value was found to be $2.34 \mathrm{eV}$. The electrical studies revealed the semiconducting nature of CdS films with electrical resistivity in the order of $10^{5} \Omega \mathrm{cm}$ and activation energy $0.4 \mathrm{eV}$.
\end{abstract}

Keywords: Chalcogenide, chemical synthesis, CdS, structural properties, optical properties. electrical resistivity

\section{Introduction}

The synthesis and characterization of discrete nanocrystals are of significant importance for both fundamental and applied research. In recent year's semiconductor nanostructure such as nanoparticles, nanotubes, nanorods and nanowires have attracted intensive interest due to their physicochemical properties. Among cadmium sulphide $(\mathrm{CdS})$ is a brilliant II-VI wide band gap semiconductors with its direct band gap of $2.42 \mathrm{eV}$ for cubic phase and $2.57 \mathrm{eV}$ for hexagonal phase or the mixture of both which depend on the deposition methods and conditions ( $\mathrm{Li}$ et al. 2016, Cho et al. 2014, Enriquez and Mathew 2003) at room temperature is a promising material with many outstanding physical and chemical properties, which has applications in many technical fields including photo-chemical catalysis, gas sensor, solar cells, nanorod super lattices, field effect transistors, light emitting diodes, nonlinear optical materials, various luminescence devices and so on (Low et al., 2011, Ramaiah et al. 2001, Han et al. 2015, Kim et al. 2010, Flores-Marquez et al. 2015, Romeo et al. 2004, Arreola-Jardon et al. 2010).

There are many literature reports about $\mathrm{CdS}$ films are fabricated by different growth techniques such as chemical bath deposition (CBD), successive ionic layer adsorption and reaction (SILAR), vacuum evaporation, sputtering, electro deposition, spray pyrolysis, pulsed laser deposition, sol gel, closed space sublimation, molecular beam epitaxy, screen coating (Mathieu et al. 1995, Rao et al. 1997, 
Salata et al. 1994, Pathinettam et al. 2005, Shadia et al. 2009, Yadav et al. 2010, Yadav et al. 2010, Zelaya-Angel et al. 2000, Masumdar et al. 2003, Mikkel et al. 2008, Kumar et al. 2017, Kumar et al. 2016).

Among these entire methods screen coating is a cost-effective, simple and easy technique. In recent times screen coating films are gaining more consideration because of their broad applications such as in optoelectronic devices, solar cells and photovoltaic devices (Tomakin et al. 2011, Roy et al. 2006). The main objective of this paper is to seek the application of screen coated $\mathrm{CdS}$ alloy film for utilizing these films in semiconductor device fabrication. Hence, in this paper, we have presented the elemental, morphological, optical, structural and electrical properties of the screen coated cadmium sulphide thick films.

\section{Experimental details}

In the present work, powder of $\mathrm{CdS}$ nanoparticles was prepared by the chemical co-precipitation method using AR grade cadmium acetate $\mathrm{Cd}\left(\mathrm{CH}_{3} \mathrm{COO}\right)_{2} .2 \mathrm{H}_{2} \mathrm{O}$ and sodium sulfide $\left(\mathrm{Na}_{2} \mathrm{~S} .9 \mathrm{H}_{2} \mathrm{O}\right)$ as a starting compounds. Chemical reaction was carried out at room temperature. $50 \mathrm{ml}$ solution of $1 \mathrm{M}$ $\mathrm{Cd}\left(\mathrm{CH}_{3} \mathrm{COO}\right)_{2} .2 \mathrm{H}_{2} \mathrm{O}$ and $50 \mathrm{ml}$ solution of $1 \mathrm{M} \quad \mathrm{Na}_{2} \mathrm{~S} .9 \mathrm{H}_{2} \mathrm{O}$ were prepared separately using distilled water. Then dissolved solutions of sodium sulfide were added drop wise into cadmium acetate solution and the mixture continuously and vigorously stirred for 3 hours at constant stirring at $800 \mathrm{rpm}$, to react completely and homogeneity of the material then a dark yellow CdS precipitate formed which was filtered out and washed several times with distilled water and methanol. Finally, the product was dried for $24 \mathrm{~h}$ in dry air. After drying the precipitate was crushed to fine powder by grinding process using a mortar and pestle. This powder was used for the preparation of $\mathrm{CdS}$ thick film by using screen printing method.

A thixotropic paste was prepared by mixing synthesized CdS powder with ethyl cellulose (Ethocel)(BDH limited Poole England), a temporary binder in a mixture of organic solvents such as butyl cellosolve, 1 Acetoxy-2 butoxy ethane, and terpinolanhydrous borrowed from Loba chemical Pvt. Ltd. The prepared paste was screen-printed on pre-cleaned corning microscopic glass sides of $1 \mathrm{~mm}$ thickness. The pre-clean were carried out thoroughly by embry powder, acetone and then by deionized water. The prepared samples were dried under the IR lamp and then fired at $120{ }^{\circ} \mathrm{C}$ for $1 \mathrm{~h}$ to remove organic binder and to avoid the cracks in the films (Zargar et al. 2015, Kumar et al. 2018). The thickness of films was estimated after sintering by gravimetric weight difference method and was found to be order of $1 \mu \mathrm{m}$.

\section{Characterization}

The thick films of $\mathrm{CdS}$ were characterized for structural, morphological, optical, electrical properties. The CdS film thickness was measured by a gravimetric weight difference method and comes out $1 \mu \mathrm{m}$. The investigation of structural properties to pristine CdS films was done by XRD (AXS D8 Advance, Bruker). The measurements for all samples were performed at room temperature to detect 
any possible diffraction line within $2 \theta$ range $20-80^{\circ}$ with increment $0.02^{\circ}$ and scan speed of 0.5 sec. Surface investigation was carried out using FESEM S-4800, type II Hitachi High Technologies Corporation, Japan with accelerating voltage $20 \quad \mathrm{KV}$. Compositional analysis was made using "Bruker" AXS GmbH, made X-flash 5030 EDS attachment and Ion sputter E 1010 for gold coating of samples was employed in the present investigation. The optical properties of pristine $\mathrm{CdS}$ films were determined by JASCO V-630 UV-VIS spectrophotometer in a wavelength range of 500-1000 $\mathrm{nm}$. The dark electrical resistivity measurement was carried out using standard two probe technique. Silver paste was employed to CdS thick films to ensure good electric ohmic contacts.

\section{Results and discussion}

\section{Structural studies}

The structural investigation of nanopowder and pristine $\mathrm{CdS}$ thick film was studied by $\mathrm{X}$-ray diffraction with $\mathrm{Cu}$ $\mathrm{K} \alpha\left(\lambda=1.5406 \mathrm{~A}^{\circ}\right)$ in the range of $2 \theta$ angle from $20^{\circ}$ to $80^{\circ}$. Fig. 1 (a) shows XRD pattern of synthesized powder of $\mathrm{CdS}$ nanoparticles, which showed well resolved peaks indicating the formation of pure CdS compound. The XRD pattern of pristine $\mathrm{CdS}$ film is as shown in Fig. 1(b). The crystallographic parameters are presented in Table 1. From comparison of observed and standard ' $d$ ' values for $h \mathrm{kl}$ planes it is clear that $\mathrm{CdS}$ is a mixture of cubic, hexagonal and orthorhombic phases (Pavaskar et al. 1997, Deshmukh et al. 1995, Wu et al. 1974, Patil et al. 1998).
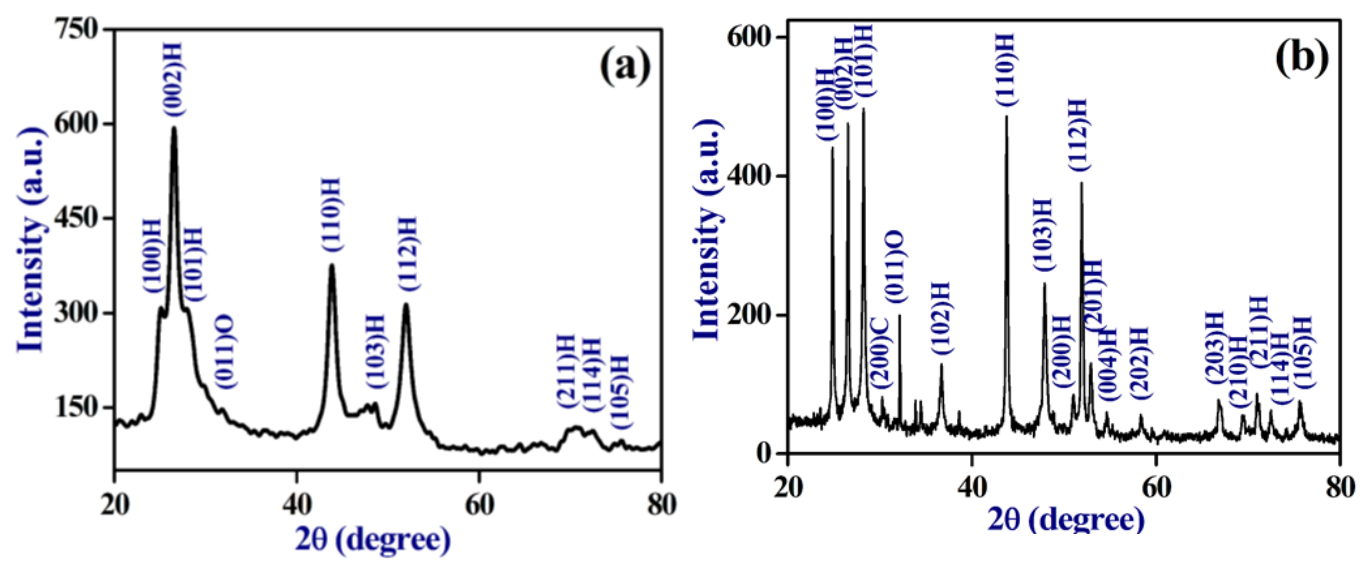

Fig. 1: X-ray diffractogram of (a) CdS powder, (b) pristine CdS thick films

In Fig. 1(a) powder XRD spectra higher intensity peaks at around $2 \theta \approx 26.54^{\circ}$, $43.88^{\circ}, 51.97^{\circ}$ reveals a hexagonal phase of cadmium sulphide, which are matched with the standard JCPDS card no.80-0006. These peaks could be assigned to the planes (002), (110) and (112) respectively of hexagonal phase. From Fig.1(b) the well-defined peaks at $2 \theta \approx 24.87^{\circ}, 26.53^{\circ}$, $28.23^{\circ}, \quad 43.97^{\circ}, \quad 47.93^{\circ}$ and $51.93^{\circ}$ corresponds to reflections from (100), (002), (101), (110), (103) and (112) planes 
of pure hexagonal $\mathrm{CdS}$ phase, respectively. From XRD spectra, it is clear that cadmium sulphide films are polycrystalline in nature having hexagonal lattice structure. The lattice parameter a and $\mathrm{c}$ of hexagonal phase was calculated using the equation (Spalatu et al. 2015).

$$
\frac{1}{d^{2}}=\frac{4}{3}\left(\frac{h^{2}+h k+k^{2}}{a^{2}}\right)+\frac{l^{2}}{c^{2}}
$$

Here h, k, 1 are Miller indices and $\mathrm{d}$ is inter-planer spacing.

The calculated value of lattice parameter 'a and c' of cadmium sulphide for powder and film was found to be $3.874 \AA$, 6.7104 $\AA$ and $3.6464 \AA, 6.3158 \AA$ respectively. The average crystallite size of cadmium sulphide film was estimated using Scherrer's formula.

$$
\mathrm{D}=\frac{0.94 \lambda}{\beta_{2 \theta} \cos \theta}
$$

Here, $\lambda$ is the wavelength, $\beta_{2 \theta}$ is the full width at half-maxima (FWHM) of the diffraction peak and $\theta$ is the Bragg's angle. The average size of crystallites was found to be $12.81 \mathrm{~nm}$ and $31.41 \mathrm{~nm}$ for powder and $\mathrm{CdS}$ film respectively. The micro strain, which is an interesting structural parameter, was calculated using the relation:

$$
\varepsilon=\frac{\beta_{2 \theta}}{4 \tan \theta}
$$

The dislocation density $(\delta)$ was estimated using the relation:

$$
\delta=\left(\frac{1}{D^{2}}\right)
$$

The number of crystallites per unit area $(\mathrm{N})$ was calculated using the relation:

$$
\mathrm{N}=\left(\frac{\mathrm{t}}{\mathrm{D}^{\mathrm{s}}}\right)
$$

In present report, micro strain, dislocation density and number of crystallites per unit area of cadmium sulphide films were found of the order of $1.63 \times 10^{-2}$ lines $^{-2} \mathrm{~m}^{-4}$,

\begin{tabular}{|c|c|c|c|c|c|c|c|c|c|c|}
\hline \multirow[t]{2}{*}{$\begin{array}{l}\text { Powder } \\
\text { Sample }\end{array}$} & \multirow[t]{2}{*}{$2 \theta^{\circ}$} & \multirow[t]{2}{*}{$F W H M$} & \multirow[t]{2}{*}{$(h k l)$} & \multicolumn{2}{|l|}{$d(\AA)$} & \multicolumn{2}{|c|}{$a=b(\AA)$} & \multicolumn{2}{|l|}{$c(\AA)$} & \multirow[t]{2}{*}{$\begin{array}{l}D \\
(\mathrm{~nm})\end{array}$} \\
\hline & & & & Obs. & Std. & Obs. & Std. & Obs. & Std. & \\
\hline S1 & 26.54 & 0.6369 & (002) & 3.3550 & 3.3410 & 3.874 & 4.121 & 6.7104 & 6.682 & 12.81 \\
\hline
\end{tabular}
$1.01 \times 10^{11}$ lines $/ \mathrm{cm}^{2}$ and $8.06 \times 10^{12} \mathrm{~cm}^{-2}$. Films having lower strain and dislocation density improve the stoichiometry of the

\begin{tabular}{|c|c|c|c|c|c|c|c|c|c|c|}
\hline \multirow{2}{*}{$\begin{array}{l}\text { Film } \\
\text { Sample }\end{array}$} & \multirow[t]{2}{*}{$2 \theta^{\circ}$} & \multirow[t]{2}{*}{$F W H M$} & \multirow[t]{2}{*}{$(h k l)$} & \multicolumn{2}{|l|}{$d(\AA)$} & \multicolumn{2}{|l|}{$a=b(\AA)$} & \multicolumn{2}{|l|}{$c(\AA)$} & \multirow{2}{*}{$\begin{array}{l}D \\
(\mathrm{~nm})\end{array}$} \\
\hline & & & & Obs. & Std. & Obs. & Std. & Obs. & Std. & \\
\hline S1 & 28.23 & 0.2607 & (101) & 3.1579 & 3.1480 & 3.6464 & 4.121 & 6.3158 & 6.682 & 31.41 \\
\hline
\end{tabular}
films (Kumar et al. 2016).

Table 1: X-ray diffraction data of CdS nanopowder prepared by co-precipitation method

Table 2: X-ray diffraction data of pristine CdS thick film 


\section{Surface morphology and EDAX analysis}

FE-SEM is a promising technique, which provides valuable information regarding the growth mechanism, shape and size of the particles. The surface morphology of screen-printed cadmium sulphide films were examined through FESEM. The FE-SEM image of screenprinted cadmium sulphide film is depicted in Fig. 2. at 40,000 x magnifications. It can be seen that the grains of nano size morphology with uniformly distributed nearly spherical clusters. The average grain size observed was $180 \mathrm{~nm}$. The results are well supported by earlier reported work of (Yadav et al. 2010)

The quantitative analysis of cadmium (Cd) and sulphur (S) present in the films were carried out using EDAX technique. Fig. 3 represents the EDAX spectra of cadmium sulphide screen-printed film. The average percentage of constituents of $\mathrm{Cd}$ and $\mathrm{S}$ elements was estimated as $42.70 \%$ and $57.30 \%$ respectively indicating that films contain cadmium sulphide with deficiency of cadmium. These results of EDAX indicate the prepared films were almost non-stoichiometric.

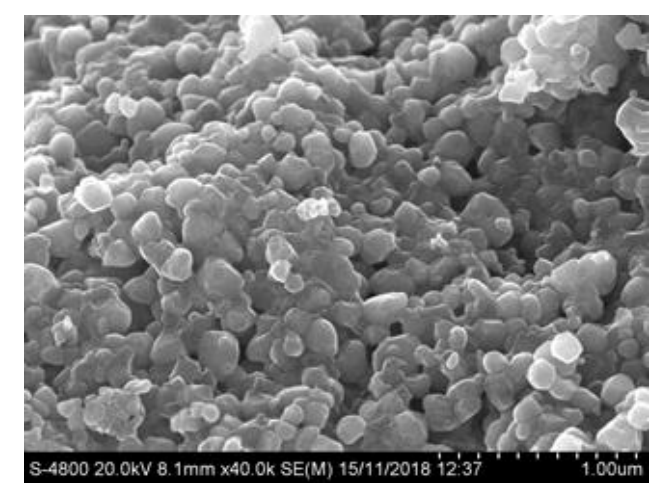

Fig. 2. FE-SEM image of screen-printed cadmium sulphide film.

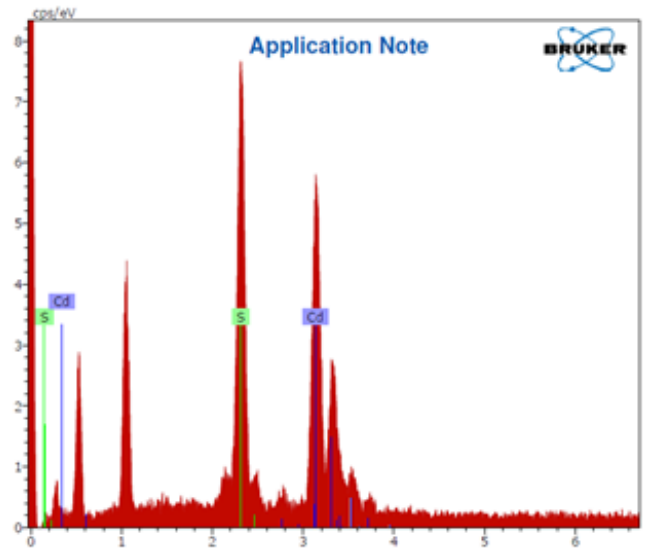

Fig. 3. EDAX spectra of screen-printed cadmium sulphide film.

\section{Optical studies}

The optical absorbance and transmittance spectra of pristine CdS thick film were carried out employing a UV-Vis spectrophotometer (JASCO V-630) at room temperature in the wavelength range 500-1000 nm and presented in Fig. 4.

It is visible in Fig. 4 that the CdS thick films showed good optical absorbance in the visible region and observed to be decreased with increase in wavelength which might be ascribed to the charge carrier absorption. The absorbance is found $1.68 \%$ in lower wavelength range and found to decrease with increase in wavelength for pristine films.

The optical transmittance is found to be increased at higher wavelength range that revealed to the homogeneous nature of deposited thick films (Islam et al. 2013) agreed with the reported work of (Samantilleke et. al. 2011). Generally, the optical transmittance of thick films is affected by the film thickness, surface morphology and defects at the grain boundaries (Revathi et al. 2008). The optical energy band gap (Eg) was determined by relation for near edge 
absorption of compound semiconductors (Spalatu et al. 2015).

$$
\alpha h v=A(h v-E g)^{\mathrm{n} / 2}
$$

Here, $\alpha$ is the absorption coefficient, $h$ is the plank constant, $v$ is the frequency of light, $\mathrm{A}$ is a constant, $\mathrm{Eg}$ is the optical energy band gap and $\mathrm{n}$ is an integer. The absorption coefficient $(\alpha)$ was calculated from the relation concerned (Chander and Dhaka 2017).

$$
\alpha=\frac{2.303 \mathrm{~A}}{\mathrm{t}}
$$

The refractive index (n) was calculated using Herve-Vandamme formula:

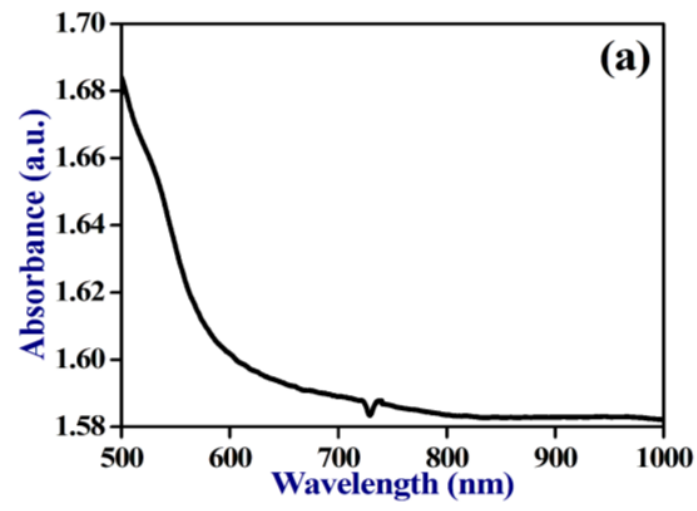

$$
n^{2}=1+\left(\frac{\mathrm{A}}{\mathrm{E}_{\mathrm{B}}+\mathrm{B}}\right)^{2}
$$

The $(\alpha h v)^{2}$ v/s hv plot of the pristine films are shown in Fig. 5. The Tauc plot of pristine films is observed to be approximately linear which show that the transition between conduction band and valance band is found to be direct. The optical band gap of pristine films is 2.34 $\mathrm{eV}$. The refractive index it is found 2.57. The optical absorption coefficient comes out to be $1.54 \times 10^{4} \mathrm{~cm}^{-1}$

Fig. 4:(a) Optical absorbance spectra (b) transmittance spectra of screen-printed cadmium sulphide film.

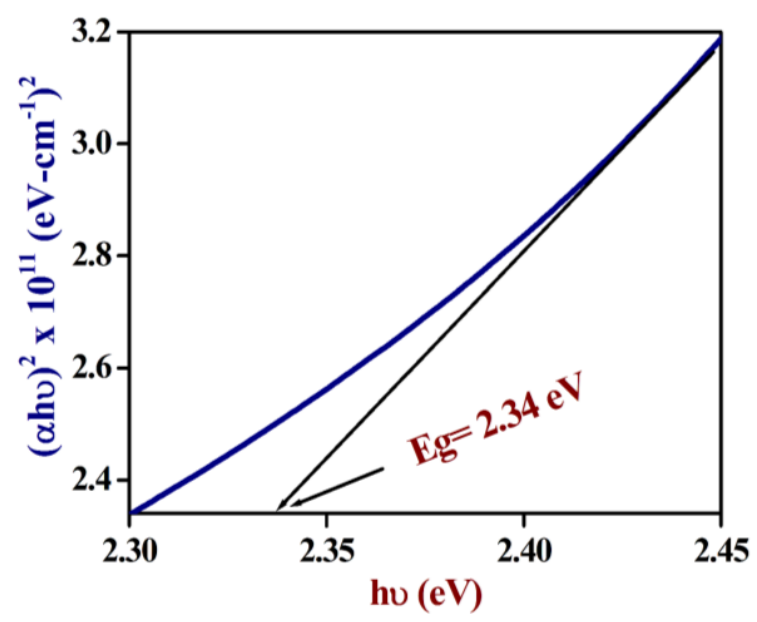

Fig. 5: Energy band gap determination of screen-printed cadmium sulphide film from absorption spectra. 


\section{Electrical analysis}

Dark electrical resistivity is a significant parameter which offers valuable information with reference to transport phenomenon and other properties of materials for employing them in semiconductor device applications (Kumar et al. 2003). The dark dc electrical resistivity of the pristine thick film sample was measured in $300-423{ }^{\circ} \mathrm{K}$ temperature range onrectangular-shaped samples with typical size of $20 \mathrm{~mm}^{2}$, using DC twopoint probe method under dark. The variation of $\log$ of resistivity $(\log \rho)$ with reciprocal of temperature $(1000 / T)$ for screen-printed cadmium sulphide films for a cooling cycle is depicted in Fig. 6. The activation energies of electrical conduction have been determined using the following Arrhenius relation:

$$
\rho=\rho_{0} \exp \left(\frac{E_{a}}{K_{B} \mathrm{~T}}\right)
$$

where $\rho$ is the resistivity at temperature T, $\rho_{0}$ is a constant, $K_{B}$ is Boltzman's constant, $\mathrm{T}$ is the absolute temperature and $\mathrm{E}_{\mathrm{a}}$ is the activation energy. The decrease in resistivity with increase in temperature confirms the semiconducting nature of the film (Yadav et al. 2010). The room temperature electrical resistivity values (low and high region) of the thick films are in the range between $2.02 \times 10^{5}$ and 6.21 $\mathrm{x} 10^{5} \Omega \mathrm{cm}$. The activation energy of cadmium sulphide film was calculated from the slope of the graph (Fig. 6). The activation energy of cadmium sulphide film was estimated to be $0.4 \mathrm{eV}$, at low temperature. The value of resistivity and activation energy reported in this study is in good agreement with the previous results.

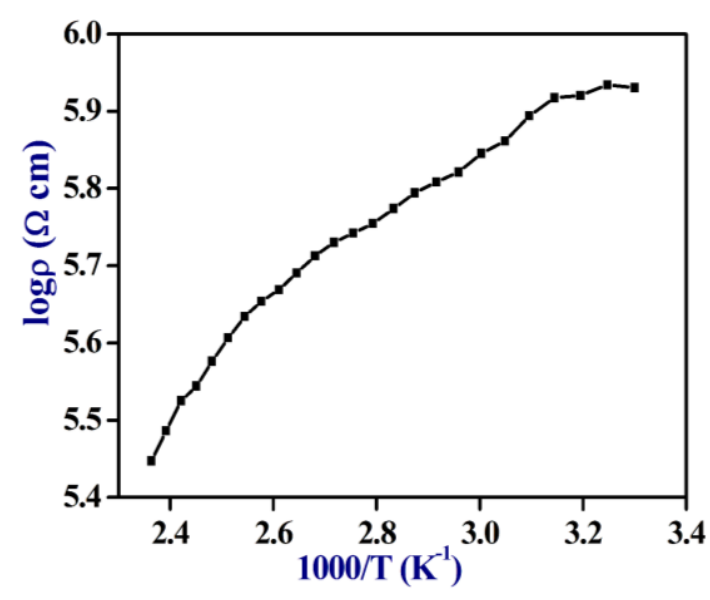

Fig. 6. Variation in logresistivity with reciprocal of temperature for screenprinted CdS thick films.

\section{Conclusions}

In this paper, a study of n-CdS thick film deposition on glass substrates is possible using a simple and economical screen coating route. A systematic study on the structural and optical properties of $\mathrm{CdS}$ films along with investigation of electrical, morphological and elemental composition is undertaken. The thick films of thickness $1 \mu \mathrm{m}$ were grown on glass substrates employing by using powder of $\mathrm{CdS}$ nanoparticles synthesized using chemical co-precipitation method, followed by sintering at low temperature. The XRD patterns reveal that the powder and films have preferred orientation (002) and (101) respectively have wurtzite structure of hexagonal phase and polycrystalline in nature. The structural parameters like inter-planner spacing, lattice constant, grain size, dislocation density, strain and number of crystallites per unit area were calculated. The interplanner spacing and lattice constant are in good agreement with the standard data. The crystalline size is found to be for 
powder and film is 12.81 and $31.41 \mathrm{~nm}$ respectively. The micro strain, dislocation density and number of crystallites per unit area of cadmium sulphide films were found of the order of $1.63 \times 10^{-2}$ lines $^{-2} \mathrm{~m}^{-4}$, $1.01 \times 10^{11}$ lines $/ \mathrm{cm}^{2}$ and $8.06 \times 10^{12} \mathrm{~cm}^{-2}$. The FE-SEM studies show that the pristine films are uniform and homogeneous as well as free from crystal defects and voids. FE-SEM image reveals the porous and interconnected grains of nano size morphology with uniformly distributed nearly spherical clusters. The presence of cadmium and sulphur was confirmed by EDAX spectra. The optical parameters optical band gap, absorption coefficient and refractive index are calculated and found to be $2.34 \mathrm{eV}, 1.54 \times 10^{4} \mathrm{~cm}^{-1}$ and 2.57 respectively. The room temperature electrical resistivity values (low and high region) of the thick films are in the range between $2.02 \times 10^{5}$ and $6.21 \times 10^{5} \Omega \mathrm{cm}$. and activation energy around $0.4 \mathrm{eV}$. The electrical resistivity of the thick films was found to be decreased with increasing temperature. The results are in good agreement with the available literature. The experimental results revealed that $\mathrm{CdS}$ thick films may be used as alternative materials for eco-friendly window layer to the thin film solar cell applications.

\section{Acknowledgments}

The authors wish to acknowledge the UGC-DAE Consortium for Scientific Research Indore for providing characterization facilities. The authors wish to show gratitude to Prof. Dr. J. V. Sali (School of physical Sciences, KBCNMU, Jalgaon) and Dr. S. R. Gosavi (Arts, Commerce and Science College,
Taloda) for their help and encouragement for this work.

\section{References}

Arreola-Jardon G, Gonzalez L A, GarciaCerda L A, Gnade B, Quevedo-Lopez M A, Ramírez-Bon R (2010). Ammonia-free chemically deposited CdS films as active layers in thin film transistors, Thin Solid Films 519:517520.

Cho S H, Kim S S, Park M H, Suh J H, Hong J K (2014). Surface treatment of the window layer in $\mathrm{CdS} / \mathrm{CdTe}$ solar cells, J. Korean Phys. Soc. 65:15901593.

Chander S, Dhaka M S (2017). Optical and structural constants of CdS thin films grown by electron beam vacuum evaporation for solar cells, Thin Solid Films 638:179-188.

Deshmukh L P, Holikatti S G, More B M (1995). Optical and structural properties of antimony-doped $\mathrm{CdS}$ thin films, Materials Chemistry and Physics 39:278-283.

Enriquez J P, Mathew X (2003). Influence of the thickness on structural, optical and electrical properties of chemical bath deposited $\mathrm{CdS}$ thin films, Sol. Energy Mater. Sol. Cell 76:313-322.

Flores-Marquez J M, Albor-Aguilera M L, Matsumoto-Kuwabara Y, GonzalezTrujillo M A, Hernandez-Vasquez C, Mendoza-Perez R, Contreras-Puente G S, Tufino-Velazquez M (2015). Improving $\mathrm{CdS} / \mathrm{CdTe}$ thin film solar cell efficiency by optimizing the physical properties of $\mathrm{CdS}$ with the application of thermal and chemical 
treatments, Thin Solid Films 582:124127.

Han J F, Fu G H, Krishnakumar V, Schimper H J, Liao C, Jaegermann W, Besland M P (2015). Studies of $\mathrm{CdS} / \mathrm{CdTe}$ interface: comparison of $\mathrm{CdS}$ films deposited by close space sublimation and chemical bath deposition techniques, Thin Solid Films 582:290-294.

Islam M A, Hossain M S, Aliyu M M, Karim M R, Razykov T, Sopian K, Amin N (2013). Thin Solid Films 546:367-374.

JCPDS, International Center for Differaction Data, USA Card No.800006 (CdS, hexagonal structure).

Kim M J, Min B K, Kim C D, Lee S H, Kim H T, Jung S K, Sohn S H (2010). Study of the physical property of the cadmium sulfide thin film depending on the process condition, Curr. Appl. Phys. 10:S455-S458.

Kumar V, Agrawal S, Dwivedi D K (2017). Study on optical investigations and DC conduction mechanism in polycrystalline chalcogenide $(\mathrm{Cd}, \mathrm{Zn})$ semiconductor thin films grown by screen-printing method, J. Mater. Sci. Mater. Electron. 28:1715-1719.

Kumar V, Sharma D K, Sharma K K, Agrawal S, Bansal M K, Dwivedi D K (2016). Structural, optical and electrical characterization of nanocrystalline $\mathrm{CdO}$ films for device applications, Optik 127:4254-4257.

Kumar V, Sharma D K, Kapil Sharma, Dwivedi D K (2018). Investigation on physical properties of polycrystalline nickel sulphide films grown by simple
\& economical screen-printing method, Optik, 156:43-48.

Kumar S, Sharma T P, Zulfequar M, Husain M (2003). Characterization of vacuum evaporated $\mathrm{PbS}$ thin films, Phys. B 325:8-16.

Li Y, Song Y L, Zhou F Q, Ji P F, Tian M L, Wan M L, Huang H C, Li X J (2016). Photovoltaic properties of $\mathrm{CdS} / \mathrm{Si}$ multi-interface nanoheterojunction with incorporation of $\mathrm{Cd}$ nanocrystals into the interface, Mater. Lett. 164:539-542.

Lo Y S, Choubey R K, Yu W C, Hsu W T, Lan C W(2011). Shallow bath chemical deposition of $\mathrm{CdS}$ thin film, Thin Solid Films 520:217-223.

Mathieu H, Richard T, Allegre J, Lefebvre P, Arnaud G (1995). Quantum confinement effects of $\mathrm{CdS}$ nanocrystals in a sodium borosilicate glass prepared by the sol-gel process, J. Appl. Phys. 77:287-293.

Masumdar E U, Gaikwad V B, Pujari V B, Patil V B, Deshmukh L P (2003). Some studies on chemically synthesized antimonydoped CdSe thin films, Mater. Chem. Phys. 77:669676.

Mikkel J, Kion Norrman, Frederik C. Krebs (2008). Stability/degradation of polymer solar cells, Solar Energy Materials \& Solar Cells 92:686-714.

Pathinettam P D, Marikani A, Murali K R (2005). Optical properties of vacuum evaporated $\mathrm{Cd}_{\mathrm{x}} \mathrm{Sn}_{1-\mathrm{x}} \mathrm{Se}$ polycrystalline thin films: influence of composition and thickness Phys. B:Condens. Matter 357:485-493. 
Pavaskar N R, Menezes C A, Sinha A P B (1997). Photoconductive CdS Films by a Chemical Bath Deposition Process, J. Electrochem. Soc. 124:743-748.

Patil L A, Wani P A, Sainkar S R, Mitra A, Phatak G J, Amalnerkar D P (1998). Studies on 'fritted' thick films of photoconducting $\mathrm{CdS}$, Materials Chemistry and Physics 55:79-83.

Ramaiah K S, Pilkington R D, Hill A E, Tomlinson R D, Bhatnagar A K (2001). Structural and optical investigations on $\mathrm{CdS}$ thin films grown by chemical bath technique, Mater. Chem. Phys. 68:22-30.

Romeo N, Bosio A, Canevari V, Podesta A (2004). Recent progress on $\mathrm{CdTe} / \mathrm{CdS}$ thin film solar cells, Sol. Energy 77:795-801.

Rao A V, Pajonk G M, Parvathy N N (1997). Preparation and characterization of nanocrystalline CdS doped monolithic and transparent TEOS silica xerogels using sol-gel method, Mater. Chem. Phys. 48:234239.

Roy P, Srivastava S K (2006). In situ deposition of Sn-doped CdS thin films by chemical bath deposition and their characterization, J. Phys. D. Appl. Phys. 39:4771

Revathi N, Prathap P, Subbaiah Y P V, Reddy K T R (2008). Substrate temperature dependent physical properties of $\mathrm{In}_{2} \mathrm{~S}_{3}$ films, J. Phys. D: Appl. Phys 41:155404 (10pp).

Salata O V, Dobson P J, Hull P J, Hutchinson J L (1994). Fabrication of $\mathrm{CdS}$ nanoparticles embedded in a polymer film by gas-aerosol reactive electrostatic deposition technique, Thin Solid Films 251:1-3.

Shadia J. Ikhmayies, Riyad N. AhmadBitar (2009). Effects of processing on the electrical and structural properties of spray deposited CdS:In thin films, Phys. B: Condens. Matter 404:24192424.

Spalatu N, Hiie J, Mikli V, Krunks M, Valdna V, Maticiuc N, Raadik $\mathrm{T}$, Caraman M (2015). Effect of $\mathrm{CdCl}_{2}$ annealing treatment on structural and optoelectronic properties of close spaced sublimation $\mathrm{CdTe} / \mathrm{CdS}$ thin film solar cells v/s deposition conditions, Thin Solid Films 582:128133.

Samantilleke A P, Cerqueira M F, Heavens S, Warren P, Dharmadasa I M, Muftah G E A, Silva C J R, Mari B (2011). Characterization of chemical bath deposited $\mathrm{CdS}$ thin films on different substrates using electrolyte contacts. Thin Solid Films 519:75837586.

Tomakin M, Altunbas M, Bacaksiz E, Polat I (2011). Preparation and characterization of new window material $\mathrm{CdS}$ thin films at low substrate temperature (b300 K) with vacuum deposition, Mater. Sci. Semicond. Process. 14:120-127.

Wu C, Bube R H (1974). Thermoelectric and photo thermoelectric effects in semiconductors: Cadmium sulfide films, J. Appl. Phys. 45:648-660.

Yadav A A, Barote M A, Masumdar E U (2010). Studies on nanocrystalline cadmium sulphide (CdS) thin films 
deposited by spray pyrolysis, Solid State Sciences 12:1173-1177.

Yadav A A, Barote M A, Dongre P M, Masumdar E U(2010). Studies on growth and characterization of $\mathrm{CdS}_{1-}$ ${ }_{x} \operatorname{Se}_{x}(0.0 \leq x \leq 1.0)$ alloy thin films by spray pyrolysis, J. Alloys Compd. 493:179-185.

Zelaya-Angel O, Lozada-Morales R (2000). Sphalerite-wurtzite phase transformation in CdS, Phys. Rev. B 62:13064-13069.

Zargar R A, Chackrabarti S, Joseph S, Mohd. S. Khan, Husain R, Hafiz A K (2015). Synthesis and characterization of screen printed $\mathrm{ZnO}$ films for solar cell applications, Optik, 126:41714174. 